\title{
DIELECTRIC PARAMETERS OF AYURVEDIC MEDICINES BIOLOGICAL APPROACH
}

\author{
Uddhav Ram Lahane ${ }^{1}$, Prashant Uddhav Lahane ${ }^{2}$ \\ ${ }^{1}$ Department of Electronic Science, ShriChhatrapatiShivajiCollege (Affiliated to University of Pune), Shrigonda \\ Maharashtra, India, ${ }^{2}$ RMDSinhgadSchool of Engineering and Research, Pune, India
}

\begin{abstract}
The study of dielectric properties of biological materials is of great assistance in exploring the molecular structure and dynamics of condensed matter. Time domain reflectometry in reflection mode has been used as a technique. A nonlinear least squares fit method have been used to obtain dielectric parameters viz., static dielectric constant $\left(\varepsilon_{0}\right)$ and dielectric relaxation time $(\tau)$ at temperatures $10^{\circ} \mathrm{C}, 20^{\circ} \mathrm{C}, 30^{\circ} \mathrm{C}$ and $40^{\circ} \mathrm{C}$ of Ayurvedic Medicines.
\end{abstract}

Keywords: Medicinal plants, Asava, Ethanol,Time domain reflectometry, Fourier transformation, Dielectric constant, Relaxation time.

\section{INTRODUCTION}

Ayurveda, an ancient Indian medical science, developed in close association with natural environment. It is deeply related to the Indian cultural heritage. Its approach is to protect, cure and prolong human life. The bioregulating principles: Vayu, Pitta and Kapha pervade the whole body, their general seats being the lower, middle and upper portions of the body. The concept of body purification therapy known as Panchakarma is based on knowledge of the seats.

Prana means life in a living being. Pranasakti is nothing but energy called Vayu. This energy or the motive force is derived from the food, liquid and air we take from the external source inside our body. Vayu activates all the processes of the body. Without the activity of the Vayu, life ( prana ) cannot be there.

The cell of living plants consists of chemical compounds like carbohydrates, proteins, fats etc. Human utilizes these compounds as food matter. There are other compounds like alkaloids, tannins glycosides etc. and these compounds exert physiological effects and used as therapeutic agents. The medicinal plants and herbal products, products of metals, salts gems and poisons are used for therapeutic purposes. Ayurvedic compound formulation are divided into two groups: plant drugs ( Kasthausadhi ), metals and minerals ( Rasausadhi ). Ayurvedic medicines Asava and Arista are made by soaking the drugs either in powder or in decoction forms in a solution of sugar or jiggery, for a specified period of time. During the specified period it undergoes a process of fermentation and generates alcohol which facilitates the extraction of the active principles contained in the drugs. The alcohol also serves as a preservative. Asavas and Ariatas may use as herbal wines.The Sanskrit names of medicinal plants and metals have been used to indicate the standard names of Asava. For examples, the basic medicinal plants used in the production of Drakshasava is a Black raisin and Arvindasava is Lotus. The Sanskrit names of Black raisin (a sweet dried grape) isDraksha and Lotus is Arvind. Asava are prepared by Indian traditional methods and identified by their common names. This 'Asava' can be easily absorbed by the body, is curative and lasts long. The solute-solvent biological molecular interactions between Ayurvedic medicines, Asava and associative solvent Ethanol are presented in the paper.

\section{EXPERIMENTAL}

Time domain reflectometry (TDR) in reflection mode has been used as a technique. In TDR a fast rising step pulse of $25 \mathrm{ps}$ is incident on the mixture kept in the cell. The mixtures were prepared at different volume percentage of Panchasava in Ethanol in steps of 10 vol. \% within a \pm 0.01 $\%$ error limit. The reflected pulse from the cell is sampled with incident pulse in sampling oscilloscope. The reflected pulse from sample contains the information regarding dielectric behaviour of biological materials. The reflected pulse without sample $R_{1}(t)$ and with sample $R_{x}(t)$ were digitized in 1024 points and stored on disc.

\section{DATA ANALYSIS}

The time dependent data were processed to obtain complex reflection coefficient spectra $\rho^{*}(\omega)$ using Fourier transformation (Samulon [2]; Shannon [3]) as

$$
\rho^{*}(\omega)=\frac{c p(\omega)}{j \omega d q(\omega)}
$$

Where $p(\omega)$ and $q(\omega)$ are Fourier transforms of $\left(R_{1}(t)-R_{x}(t)\right)$ and $\left(R_{1}(t)+R_{x}(t)\right)$, respectively, $c$ is the velocity 
of light, $\omega$ is the angular frequency, and $d$ is the effective pin length.

The complex permittivity spectra $\varepsilon^{*}(\omega)$ were obtained from reflection coefficient spectra $\rho^{*}(\omega)$ by using the bilinear calibration method (Cole [4] et al.). The experimental values of $\varepsilon^{*}(\omega)$ are fitted with the Debye equation (Havriliak and Negami [5]; Cole and Cole [6]; Davidson and Cole [7])

$$
\varepsilon *(\omega)=\varepsilon_{\infty}+\frac{\varepsilon_{0}-\varepsilon_{\infty}}{(1+j \omega \tau)}
$$

with $\varepsilon_{0}, \varepsilon_{\infty}$ and $\tau$ as fitting parameters. A nonlinear leastsquares fit method (Bevington [8] ) was used to determine the values of dielectric parameters. The values of static dielectric constant $\left(\varepsilon_{0}\right)$ and dielectric relaxation time $(\tau)$ are listed in table 1.

Table 1: Temperature dependent dielectric parameters for Panchasava-Ethanol mixture

\begin{tabular}{|c|c|c|c|c|c|c|c|c|}
\hline \multirow{2}{*}{$\begin{array}{c}\text { Volume fraction of } \\
\text { panchasava }\end{array}$} & \multicolumn{2}{|c|}{$10^{0} \mathrm{C}$} & \multicolumn{2}{|c|}{$20^{\circ} \mathrm{C}$} & \multicolumn{2}{|c|}{$30^{\circ} \mathrm{C}$} & \multicolumn{2}{|c|}{$40^{\circ} \mathrm{C}$} \\
\hline & $\varepsilon_{0}$ & $\tau p s$ & $\varepsilon_{0}$ & $\tau p s$ & $\varepsilon_{0}$ & $\tau p s$ & $\varepsilon_{0}$ & $\tau p s$ \\
\hline 0.0 & 26.85 & 167.04 & 25.91 & 150.77 & 25.23 & 128.08 & 24.52 & 111.29 \\
\hline 0.1 & 32.22 & 143.38 & 30.52 & 114.95 & 29.21 & 99.01 & 28.23 & 87.93 \\
\hline 0.2 & 36.47 & 112.81 & 35.09 & 98.70 & 33.76 & 86.30 & 32.47 & 77.23 \\
\hline 0.3 & 42.30 & 98.51 & 40.85 & 87.05 & 39.45 & 75.09 & 38.17 & 67.01 \\
\hline 0.4 & 47.68 & 91.87 & 45.84 & 80.45 & 44.94 & 68.40 & 42.95 & 61.34 \\
\hline 0.5 & 53.73 & 86.62 & 52.85 & 75.87 & 50.46 & 63.47 & 48.43 & 58.14 \\
\hline 0.6 & 59.97 & 75.56 & 58.49 & 70.30 & 56.24 & 58.93 & 53.93 & 55.12 \\
\hline 0.7 & 65.83 & 69.16 & 65.15 & 68.12 & 61.34 & 53.34 & 58.94 & 51.35 \\
\hline 0.8 & 71.31 & 58.20 & 69.21 & 57.59 & 65.66 & 46.02 & 63.91 & 45.03 \\
\hline 0.9 & 75.34 & 50.74 & 73.25 & 49.97 & 69.28 & 42.97 & 67.86 & 41.70 \\
\hline 1.0 & 77.71 & 41.84 & 77.12 & 40.39 & 73.22 & 38.19 & 71.49 & 37.20 \\
\hline
\end{tabular}

\section{RESULT AND CONCLUSION}

When a molecular system is placed in an electric field, there is always the tendency for the electrically charged species to move along the appropriate direction, causing the atom to develop an induced dipole moment. The amount of polarization depends on factors such as size of molecule, effective dipole moment, and temperature. Relaxation time of biological material can be related to the

size of molecule, mobility of molecules in liquid, molecular volume, viscosity and temperature. Decrease in relaxation time can be correlated to decrease in size of molecule as well as to increase in mobility of molecules in liquid. Relaxation time decreases with increasing volume of Panchasava in solution. The smaller structures may be formed due to breaking of long chain multimeric structures in ethanol.

\section{REFERENCES}

[1].Grant E. H. Dielectric behaviour of biological molecules in solutions. Clarendon press Oxford 1978

[2].Samulon H.A. Spectrum analysis of transient response curves, Proc. IRE 1951,39,175-186.

[3].Shannon C.E., Communication in the presence of noise, Proc. IRE 1949,37,10.

[4].Cole R.H.; Berbarian J.G.; Mashimo S.; Chryssikos G.; Burns A.; Tombari E. Time domain reflection methods for dielectric measurements to $10 \mathrm{GHz}$,

J. Appl. Phys. 1989,66,793-802.
[5].Havriliak S. \&Negami S. A complete plane analysis of $\alpha$-dispersionin some polymer systems J. Polym. Sci. Polym. Symp. 1966,99-117.

[6].Cole K.S. \& Cole R.H. Dispersion and absorption in dielectrics, J.Chem. Phys. 1941,9,341-345.

[7].Davidson D.W.; Cole R.H. Dielectric relaxation in Glycerin, J. Chem. Phys. 1950,18,1417.

[8].Bevington P. R., Data reduction and error analysis for the physical sciences; McGraw Hill: New York, 1969. 